\title{
Feasibility of In Situ Arsenic Immobilisation in a Highly Contaminated Coastal Aquifer
}

Alyssa BARRON ${ }^{1,2}$, JiNG SUN ${ }^{1,2}$, BEN BOSTICK ${ }^{3}$, JAMES JAMIESON $^{1,2}$, NiCOLÒ COLOMBANI ${ }^{3}$, MARCO PETITA ${ }^{3}$, MAURIZIO BARBIERI $^{3}$ AND HENNING PROMMER ${ }^{1,2^{*}}$

${ }^{1}$ School of Earth Sciences, University of Western Australia, Crawley, WA, Australia (*Henning.Prommer@csiro.au) ${ }^{2} \mathrm{CSIRO}$ Land and Water, Floreat, Australia

${ }^{3}$ Lamont-Doherty Earth Observatory, Columbia University, New York, United States

${ }^{4}$ Dept. of Earth Sciences, "Sapienza" University of Roma, Roma, Italy

Groundwater contamination by arsenic (As) is a widespread problem in many industrialised countries. To mitigate this problem various in situ As remediation techniques have been developed over the past decade. Often these techniques rely on the use of specific amendments that manipulate the geochmemical conditions towards those favouring the formation of $\mathrm{Fe}$-oxides. Arsenic immobilisation is achieved via co-precipitation during $\mathrm{Fe}$-oxide formation and through sorption on the Fe-oxide surface. However, at many As contaminated sites, such as landfills, that are dominated by reducing conditions As associated with the neo-formed $\mathrm{Fe}-$ oxides is often susceptible to remobilsation. At the laboratory-scale the in situ generation of the mixed-valence mineral magnetite through $\mathrm{Fe}(\mathrm{II})$ and $\mathrm{NO}_{3}$ amendments has been shown to succesfully immobilise arsenic while being resistant to reduction [1,2]. In this combined laboratory-scale experimental and modelling study, we further investigate the feasibility of applying in situ magnetite generation to a severely As-polluted coastal aquifer.

Microcosm experiments were performed for a wide range of geochemical conditions, including those reflecting potential barriers to As removal efficiency, including the very high dissolved As concentrations of up to $4 \mathrm{mg} / \mathrm{L}$, (high) salinity and elevated phosphate concentrations. The microcosms representated combinations of three sediment and six solution types.

Subsequently we developed and applied a PHREEQCbased [3] kinetic geochemical modelling framework to analyse the well-documented experimental data set with the aim to derive deeper mechanistic insights on which processes control As immobilisation, or the lack thereof, under the variety of tested geochemical conditions.

[1] Chemosphere 144 (2016) 1106-1115

[2] Environ. Sci. Technol. 2018, 52, 9243-9253

[3] http://pubs.usgs.gov/tm/06/a43/ 